\title{
Photodynamic therapy combined with antivascular endothelial growth factor treatment for recalcitrant chronic central serous chorioretinopathy
}

This article was published in the following Dove Press journal:

Clinical Ophthalmology

Number of times this article has been viewed

\author{
Masumi G Asahi' \\ Andrew T Chon' \\ Esmeralda Gallemore' \\ Ron P Gallemore ${ }^{1,2}$ \\ 'Clinical Research Department, Retina \\ Macula Institute, Torrance, CA, USA; \\ 2Jules Stein Eye Institute, University of \\ California, Los Angeles, CA, USA
}

Purpose: To determine whether combination photodynamic therapy (PDT) and antivascular endothelial growth factor (VEGF) therapy is effective in the management of chronic central serous chorioretinopathy (CSC) recalcitrant to conventional therapy.

Methods: This was a retrospective analysis of eight patients with chronic CSC unresponsive to topical nonsteroidal anti-inflammatory drugs, focal photocoagulation, anti-VEGF alone, or PDT alone. All patients were evaluated with a full ophthalmic examination, spectral-domain optical coherence tomography (OCT), fluorescein angiography (FA), and most with indocyanine green angiography (ICGA) followed by treatment with half-fluence PDT and intravitreal anti-VEGF injection (seven bevacizumab, one aflibercept). Patients were seen in follow-up 1 month after treatment.

Results: All eight patients achieved complete resolution in subretinal fluid following combination treatment. Average duration of CSC prior to initiation of combination therapy was 7.5 months. Mean central macular thickness on OCT decreased significantly from $401.2 \pm 52.7 \mu \mathrm{m}$ to $297.9 \pm 18.2 \mu \mathrm{m}(p=0.0010)$ by 4 months after treatment (1.63 \pm 1.18 months). Seven of eight patients were followed up for an average of 13 months with no recurrence during that time. One case recurred at 8 months and was treated with repeat combination at that time. Frank choroidal neovascularization (CNV) was not identified in these cases on FA or ICGA studies. Eight of eight patients showed significant improvement in vision from a $\log$ MAR of $0.1125 \pm 0.099$ to $0.0125 \pm 0.064$ ( $p=0.019)$.

Conclusion: Combination PDT and anti-VEGF is effective for chronic CSC which has failed conventional therapy. Associated CNV and/or inflammation may be reasons for greater success in patients treated with combination therapy.

Keywords: anti-VEGF, chronic central serous chorioretinopathy, combination, photodynamic therapy, recalcitrant

\section{Introduction}

Central serous chorioretinopathy (CSC) is believed to result from focal leakage through the retinal pigment epithelium (RPE) with resulting serous detachment of the neurosensory retina. ${ }^{1}$ While the acute form of CSC generally resolves spontaneously with minimal sequelae, the chronic form can result in widespread RPE damage and photoreceptor death secondary to chronic subretinal fluid accumulation. In approximately $30 \%-50 \%$ of cases of CSC, there may be recurrence and irreversible vision loss because of chronic neurosensory retinal detachment and atrophy of both RPE and photoreceptors. $^{2}$ In addition, chronic CSC can be complicated by choroidal neovascularization (CNV) that can lead to severe vision loss..$^{3,4}$
Correspondence: Ron P Gallemore Retina Macula Institute, 420I Torrance Boulevard, Suite 220, Torrance, CA 90503, USA

$\mathrm{Tel}+\mathrm{I} 3109449393$

Fax +I 3109443393

Email rongallemoremd@gmail.com 
Given the self-limited course of acute CSC, traditional treatment includes observation and lifestyle modifications. ${ }^{5}$ For persistent leakage or in patients desiring rapid recovery, therapeutic strategies have included thermal and nonthermal photodynamic therapy (PDT), intravitreal injection of antivascular endothelial growth factor (VEGF) drugs, diuretics, nonsteroidal anti-inflammatory drugs (NSAIDs), and mineralocorticoid receptor antagonists. ${ }^{1}$

Currently, focal laser and PDT remain the mainstay of treatment for chronic CSC. ${ }^{1}$ As observed through fluorescein angiography (FA), thermal laser photocoagulation to the site of leakage or in the vicinity shortens the duration of macular detachment. However, this has been associated with RPE damage and in some cases, iatrogenic CNV. ${ }^{6}$ Indocyanine green angiography (ICGA) guided nonthermal PDT with verteporfin (Visudyne; Novartis International AG, Basel, Switzerland) not only has led to anatomic and functional improvement of CSC but also carries the potential secondary complications of RPE atrophy and CNV seen in the use of PDT. ${ }^{7,8}$

We report a series of combination treatments utilizing half-fluence PDT $\left(300 \mathrm{~mW} / \mathrm{cm}^{2}\right.$ for 83 seconds with light dose $25 \mathrm{~J} / \mathrm{cm}^{2}$ ) with anti-VEGF therapy to treat cases of recalcitrant chronic CSC. Half-fluence PDT is reported to cause less ischemia at the level of the RPE and choriocapillaris, thus demonstrating a safer and more efficacious treatment modality when compared to conventional fullfluence PDT. ${ }^{8}$ In certain studies, intravitreal bevacizumab (Avastin; Genentech, Inc., South San Francisco, CA, USA) has been associated with visual improvement and reduced neurosensory detachment with fewer adverse effects, ${ }^{1,9}$ while another study found that Avastin has shown no benefit. ${ }^{10} \mathrm{We}$ hypothesized that the combination of PDT with anti-VEGF treatment could provide a longer lasting effect in patients with chronic CSC who have failed conventional therapy by promoting fluid absorption as well as inhibiting CNV.

\section{Patients and methods}

This retrospective study was submitted for review by the Western University of Health Sciences Institutional Review Board (IRB) for ethics approval exempt status. Approval was not granted as the IRB cannot approve a protocol submission retrospectively. As the patients in this study agreed publication of their data and cannot be identified, the Editor in Chief of the journal gave approval to proceed without ethics approval. Written informed consent was obtained from patients for publication of these cases and any accompanying images. Individual health information remained protected, and data confidentiality was maintained throughout the collection of data and writing of this article according to the
Health Insurance Portability and Accountability Act (HIPPA) Privacy Rule and Security Rule. The report is in adherence to the tenets of the Declaration of Helsinki. Patients in this review provided signed voluntary and informed consent to the described treatment and for publication of their results. Patients in this review displayed appropriate capacity to provide consent. Patients understood the risks, benefits, and alternatives for the combination therapy treatment, and understood that they were entitled to withdraw previous consent at any time during the treatment.

A retrospective analysis of eight patients who had received combination half-fluence $\mathrm{PDT}$ and anti-VEGF for the treatment of chronic CSC refractory to other treatment modalities was performed. All patients who received the aforementioned treatment between June 2014 and April 2015 at the Retina Macula Institute (Torrance, CA, USA) were included in this report. Diagnosis of CSC was based on fundoscopy, optical coherence tomography (OCT; Cirrus; Carl Zeiss Meditec AG, Jena, Germany), FA, and ICGA (Heidelberg Engineering, Heidelberg, Germany).

All cases of the combination treatment were interventional and performed on patients with chronic CSC with evidence of subretinal fluid and/or RPE detachment after failure of at least one other treatment modality which included topical NSAID, focal photocoagulation, intravitreal anti-VEGF injection, or PDT. The risks, benefits, and alternatives were discussed, and informed consent was obtained prior to initiating combination treatment.

Full-dose verteporfin (Visudyne) concentration was calculated using the body surface area and dosage calculator provided with verteporfin. The standard dose of verteporfin of $6 \mathrm{mg} / \mathrm{m}^{2}$ was used in the calculation. Verteporfin was then infused intravenously over a 10 -minute period. Five minutes after the initiation of the infusion, the eye was sterilized with ophthalmic povidone-iodine 5\%. The eye was anesthetized with topical anesthesia or $0.1 \mathrm{~mL}$ of subconjunctival $2 \%$ lidocaine.

After completing the verteporfin infusion, the eye was treated with half-fluence PDT. The laser was guided by FA and/or ICGA performed the same day with the laser delivering $25 \mathrm{~J} / \mathrm{cm}^{2}$ at an intensity of $300 \mathrm{~mW} / \mathrm{cm}^{2}$ over 83 seconds. The laser spot size was calibrated based on the area of choroidal hyperfluorescence seen in the ICGA and never exceeded 2,500 $\mu \mathrm{m}$.

Povidone-iodine 5\% was reapplied several times, and a sterile speculum was placed between the lids. An injection of $0.05 \mathrm{~mL}$ anti-VEGF was given intravitreally through the inferior pars plana with a $30 \mathrm{G}$ needle. The vision was checked following the injection to ensure the patient was 
able to count fingers at two feet following the injection with pressure applied over the eye to prevent leakage.

All patients were fully assessed at baseline and at 1 month following combination treatment. Subsequent follow-up time was variable with a progressively increasing interval until lost to follow-up. Visual acuities were measured on 20/20 scale and converted to $\log$ MAR by formula as provided in Clinical Procedures of Ocular Examination. ${ }^{11}$ Average central macular thickness was calculated as the average of the foveal and four peri-foveal quadrants displayed on OCT. Statistical analysis was performed using Data Analysis Toolpak software for Microsoft Excel.

\section{Results}

Of the eight patients included in this report, there were seven males $(87.5 \%)$ and one female $(12.5 \%)$ with a mean age of $46.25 \pm 11.18$ years (range $35-70)$. Three right eyes $(37.5 \%)$ and five left eyes $(62.5 \%)$ were treated, with an average duration of subretinal fluid associated with CSC prior to initiation of combination therapy of 4.25 months. Frank CNV was not identified in these cases on FA or ICGA studies (Figure 1). All eight cases received full-dose half-fluence PDT with the addition of anti-VEGF. Seven cases $(87.5 \%)$ were treated with bevacizumab and one case $(12.5 \%)$ with aflibercept. The clinical characteristics of each patient are demonstrated in Table 1.

All eight patients achieved complete resolution in subretinal fluid following combination treatment (Figure 2). Mean central macular thickness on OCT decreased significantly from $401.2 \pm 52.7 \mu \mathrm{m}$ to $297.9 \pm 18.2 \mu \mathrm{m}(p=0.0010)$ by 4 months after treatment ( $1.63 \pm 1.18$ months). Seven of eight patients were followed for an average of 13 months with no recurrence during that time. One case recurred at 8 months and was treated with repeat combination at that time. Eight of eight patients showed significant improvement in vision from a $\log$ MAR of $0.1125 \pm 0.099$ to $0.0125 \pm 0.064$ $(p=0.019)$.

None of the patients reported adverse systemic or infusion site effects, and no patients reported objective or subjective visual loss immediately after treatment or during any of the follow-up visits. All patients were lost to follow-up after stabilization of their vision.

\section{Discussion}

CSC ranks among the most common vision-threatening retinopathies, after age-related macular degeneration (ARMD), diabetic retinopathy, and branch retinal vein occlusion. ${ }^{12}$ Although the exact mechanism of CSC remains unknown, the current understanding of the pathogenesis emphasizes the role of the choroid, which is believed to be hyperpermeable as a result of stasis, ischemia, or inflammation with net fluid movement across the choroid into the RPE. ${ }^{3}$ The extent of visual impairment likely depends on the duration that fluid remains under the macula (subretinal space) with more rapid reabsorption of fluid limiting the extent of photoreceptor damage. In addition, continued RPE dysfunction can lead to permanent RPE damage and increased risk of CNV.

It has been reported that chronic cases of CSC can have underlying $\mathrm{CNV}$, contributing to subretinal fluid seen in CSC. ${ }^{10,13}$ Laser treatment of CSC may also cause iatrogenic $\mathrm{CNV}^{14}$ while PDT with verteporfin has been proposed to upregulate VEGF secondary to choroidal ischemia, resulting in $\mathrm{CNV}$ in some patients. ${ }^{15}$

We elected to use the combination of PDT and antiVEGF therapy to address each of the potential underlying mechanisms of subretinal fluid accumulation in chronic CSC including hyperpermeable choroid with PDT and CNV with anti-VEGF. The therapeutic mechanism of PDT in CSC is
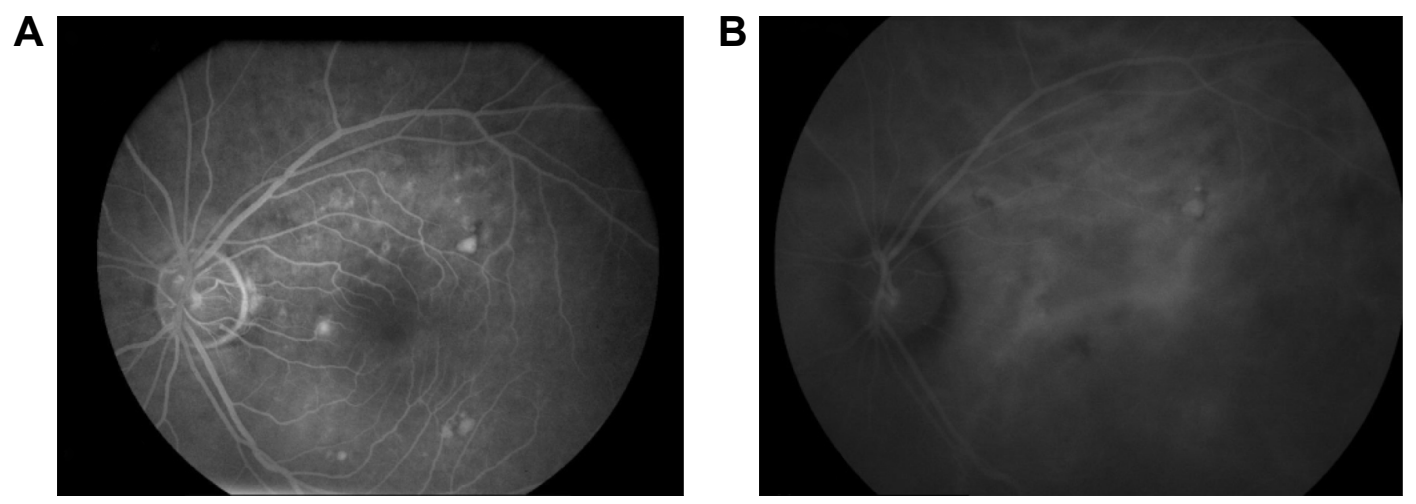

Figure I (A) FA and (B) ICGA studies of patient I prior to treatment with combination PDT and bevacizumab demonstrating (A) late focal leakage in the papillomacular bundle as well as focal staining and a PED and (B) ICGA showing increased choroidal perfusion and probable focal PED. No definitive CNV was identified.

Abbreviations: CNV, choroidal neovascularization; FA, fluorescein angiography; ICGA, indocyanine green angiography; PDT, photodynamic therapy; PED, pigment epithelial detachment. 
Table I Principal clinical characteristics of eight eyes of eight patients included in the report

\begin{tabular}{|c|c|c|c|c|c|c|c|c|c|c|}
\hline Patient & Sex & $\begin{array}{l}\text { Age } \\
\text { (years) }\end{array}$ & Eye & $\begin{array}{l}\text { Baseline } \\
\text { BCVA } \\
\text { logMAR }\end{array}$ & $\begin{array}{l}\text { Final } \\
\text { BCVA } \\
\text { logMAR }\end{array}$ & $\begin{array}{l}\text { Baseline } \\
\text { OCT average } \\
\text { macular } \\
\text { thickness }(\mu \mathrm{m})\end{array}$ & $\begin{array}{l}\text { Final OCT } \\
\text { average } \\
\text { macular } \\
\text { thickness }(\mu \mathrm{m})\end{array}$ & $\begin{array}{l}\text { Treatment failed } \\
\text { prior to initiation of } \\
\text { combination therapy }\end{array}$ & $\begin{array}{l}\text { Duration of } \\
\text { CSC prior to } \\
\text { combination } \\
\text { therapy } \\
\text { (months) }\end{array}$ & $\begin{array}{l}\text { Follow-up } \\
\text { time after } \\
\text { combination } \\
\text { therapy } \\
\text { (months) } \\
\end{array}$ \\
\hline I & Male & 46 & Left & 0.09691 & 0.0000 & 457.4 & 317.8 & $\begin{array}{l}\text { Topical NSAID, focal } \\
\text { photocoagulation } \times 3\end{array}$ & 11 & 8 \\
\hline 2 & Male & 45 & Left & 0.09691 & 0.09691 & 376.6 & 316 & $\begin{array}{l}\text { Topical NSAID, focal } \\
\text { photocoagulation }\end{array}$ & 7 & 4 \\
\hline 3 & Male & 70 & Left & 0.5440 & 0.09691 & 427 & 300 & $\begin{array}{l}\text { Intravitreal } \\
\text { bevacizumab } \times 3\end{array}$ & 6 & 3 \\
\hline 4 & Female & 53 & Right & 0.0000 & 0.0000 & 348 & 297 & $\begin{array}{l}\text { Topical NSAID, } \\
\text { intravitreal bevacizumab }\end{array}$ & 6 & 30 \\
\hline 5 & Male & 35 & Left & 0.1760 & 0.0000 & 402.2 & 286.6 & $\begin{array}{l}\text { PDT, focal } \\
\text { photocoagulation }\end{array}$ & 12 & 18 \\
\hline 6 & Male & 36 & Left & 0.0000 & -0.1249 & 430.2 & 272 & Topical NSAID & 4 & 6 \\
\hline 7 & Male & 41 & Right & 0.1760 & 0.0000 & 382.2 & 303.4 & $\begin{array}{l}\text { Topical NSAID, focal } \\
\text { photocoagulation }\end{array}$ & 6 & 15 \\
\hline 8 & Male & 44 & Right & 0.1760 & 0.0000 & 366.4 & 306.8 & $\begin{array}{l}\text { Topical NSAID, focal } \\
\text { photocoagulation }\end{array}$ & 8 & 25 \\
\hline
\end{tabular}

Abbreviations: BCVA, best-corrected visual acuity; CSC, central serous chorioretinopathy; NSAID, nonsteroidal anti-inflammatory drug; OCT, optical coherence tomography; PDT, photodynamic therapy.

believed to be through inducing narrowing and remodeling choroidal vessels, reducing choroidal exudation and subsequently the amount of subretinal fluid that accumulates. ${ }^{16}$ Half-fluence PDT has demonstrated greater success than full-fluence PDT, ${ }^{16}$ and the long-term results of half-fluence PDT for CSC have shown greater efficacy, stability, and substantial improvement in visual acuity. ${ }^{17}$ Half-dose verteporfin PDT for CSC can also be considered as long-term results show significantly better visual acuity outcomes and lower recurrence rates compared to untreated patients. ${ }^{18}$

The theoretical stimulation of fluid absorption caused by PDT can be enhanced by the addition of an anti-VEGF, which can also effectively treat any associated and subsequent CNV. ${ }^{16}$ Inoue et $\mathrm{al}^{19}$ have also shown that intravitreal bevacizumab is well tolerated in maintaining vision and reducing serous retinal detachment in chronic CSC, even 1 year after treatment. Smretschnig et $\mathrm{al}^{20}$ also found efficacy of this combined approach for chronic CSC in treatmentnaive cases associated with definitive $\mathrm{CNV}$. As noted earlier, we did not see definitive CNV in each case reported in this study. However, we suggest that the combined approach of anti-VEGF therapy with PDT should be considered for chronic CSC with or without definitive CNV identified on FA or ICGA studies as this will address any potential CNV that may be present or induced by the therapy itself.

Despite our success with the combination treatment, caution is advised with this combination treatment. Although we do not report any specific complications, intravitreal
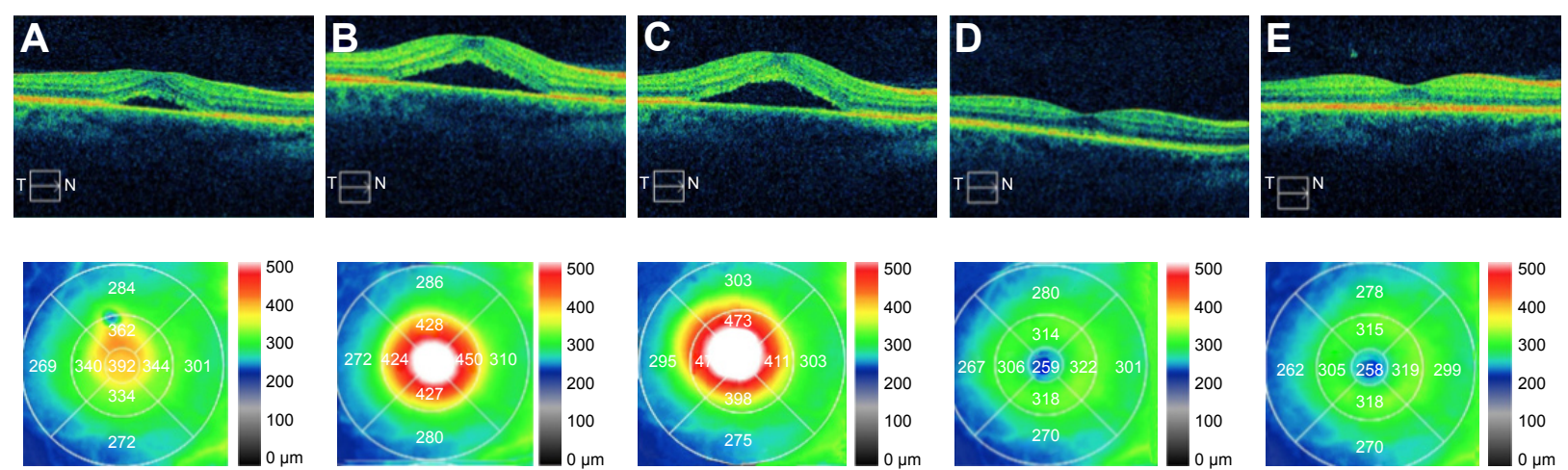

Figure 2 OCT studies and macular thickness of patient 7.

Notes: (A) Exudative detachment at the time of presentation. (B) Increasing detachment I month after topical bromfenac $0.07 \%$ and $(\mathbf{C})$ I month after focal laser. Resolution (D) 3 months and (E) 15 months after combination PDT and intravitreal bevacizumab.

Abbreviations: OCT, optical coherence tomography; PDT, photodynamic therapy. 
injections always carry the risk of postinjection endophthalmitis, vitreous hemorrhage, and retinal detachment. ${ }^{21}$ The dose of verteporfin and fluence of PDT laser have also been associated with rare complications such as choriocapillaris hypoperfusion, choroidal ischemia, and hypoxic damage caused by choriocapillaris occlusions at the site of PDT, all of which can potentially reduce vision. ${ }^{14,22}$

This retrospective study has several limitations. Our review has a smaller sample size and the cases presented are interventional treatments that were not randomized. We also did not utilize a control arm and cannot state with certainty the efficacy of our combination treatment. Future studies that utilize a larger sample size with longer follow-up periods and a control arm may be able to definitively support the efficacy of combination reduced-fluence PDT and antiVEGF for chronic CSC recalcitrant to conventional therapy. In summary, PDT combined with anti-VEGF can address both the hyperpermeable choroid and occult CNV that may be associated with chronic CSC.

\section{Conclusion}

Combination PDT and anti-VEGF is effective for chronic CSC which has failed conventional therapy. As high as 50\% recurrence rate has been reported within 1 year after treatment of the first event with conventional therapy. The addition of an anti-VEGF to PDT with verteporfin can have an additive effect in the resolution of chronic CSC and serve as prophylaxis against iatrogenic $\mathrm{CNV}$ as well as treatment of any underlying occult CNV. Associated CNV and/or inflammation may be reasons for greater success in patients treated with combination therapy. A larger randomized controlled study is needed to confirm the benefit of combination therapy for chronic CSC.

\section{Acknowledgment}

The authors thank Don Pham for his involvement with data collection.

\section{Disclosure}

The authors report no conflicts of interest in this work.

\section{References}

1. Iacono P, Parodi MB, Falcomata B, Bandello F. Central serous chorioretinopathy treatments: a mini review. Ophthalmic Res. 2016;55(2): 76-84.

2. Levine R, Brucker AJ, Robinson F. Long-term follow-up of idiopathic central serous chorioretinopathy by fluorescein angiography. Ophthalmology. 1989;96(6):854-859.
3. Nicholson B, Noble J, Forooghian F, Meyerle C. Central serous chorioretinopathy: update on pathophysiology and treatment. Surv Ophthalmol. 2013;58(2):103-126.

4. Fung AT, Yannuzzi LA, Freund KB. Type 1 (sub-retinal pigment epithelial) neovascularization in central serous chorioretinopathy masquerading as neovascular age-related macular degeneration. Retina. 2012;32(9):1829-1837.

5. Daruich A, Matet A, Dirani A, et al. Central serous chorioretinopathy: recent findings and new physiopathology hypothesis. Prog Retin Eye Res. 2015;48:82-118.

6. Chan WM, Lai TY, Lai RY, Liu DT, Lam DS. Half-dose verteporfin photodynamic therapy for acute central serous chorioretinopathy: one-year results of a randomized controlled trial. Ophthalmology. 2008;115(10):1756-1765.

7. Reibaldi M, Boscia F, Avitabile T, et al. Low-fluence photodynamic therapy in longstanding chronic central serous chorioretinopathy with foveal and gravitational atrophy. Eur J Ophthalmol. 2009;19(1): $154-158$.

8. Ma J, Meng N, Xu X, Zhou F, Qu Y. System review and meta-analysis on photodynamic therapy in central serous chorioretinopathy. Acta Ophthalmol. 2014;92(8):e594-e601.

9. Mehany S, Shaukat AM, Mohamed FS, Mourad KM. Role of Avastin in management of central serous chorioretinopathy. Saudi J Ophthalmol. 2010;24(3):69-75.

10. Chung YR, Seo EJ, Lew HM, Lee KH. Lack of positive effect of intravitreal bevacizumab in central serous chorioretinopathy: meta-analysis and review. Eye. 2013;27(12):1339-1346.

11. Kurtz D, Carlson NB, editors. Clinical Procedures of Ocular Examination. 3rd edition. New York: McGraw-Hill; 2003.

12. Wang MS, Sander B, Larsen M. Retinal atrophy in idiopathic central serous chorioretinopathy. Am J Ophthalmol. 2002;133(6):787-793.

13. Spaide RF, Campeas L, Haas A, et al. Central serous chorioretinopathy in younger and older adults. Ophthalmology. 1996;103(12):2070-2079.

14. Erikitola OC, Crosby-Nwaobi R, Lotery AJ, Sivaprasad S. Photodynamic therapy for central serous chorioretinopathy. Eye (Lond). 2014; 28(8):944-957.

15. Lee PY, Kim KS, Lee WK. Severe choroidal ischemia following photodynamic therapy for pigment epithelial detachment and chronic central serous chorioretinopathy. Jpn J Ophthalmol. 2009;53(1):52-56.

16. Nicolo M, Eandi CM, Alovisi C, et al. Half-fluence versus half-dose photodynamic therapy in chronic central serous chorioretinopathy. Am J Ophthalmol. 2014;157(5):1033-1037.

17. Rouvas A, Stavarkas P, Theodossiadis PG, et al. Long-term results of half-fluence photodynamic therapy for chronic central serous chorioretinopathy. Eur J Ophthalmol. 2012;22(3):417-422.

18. Lai TYY, Wong RLM, Chan W. Long-term outcomes of half-dose verteporfin photodynamic therapy for the treatment of central serous chorioretinopathy (An American Ophthalmological Society Thesis). Trans Am Ophthalmol Soc. 2015;113:T8.

19. Inoue M, Kadanosono K, Watanabe Y, Kobayashi S, Yamane S, Arakawa A. Results of one-year follow-up examinations after intravitreal bevacizumab administration for chronic central serous chorioretinopathy. Ophthalmologica. 2011;225(1):37-40.

20. Smretschnig E, Hagen S, Glittenberg C, et al. Intravitreal anti-vascular endothelial growth factor combined with half-fluence photodynamic therapy for choroidal neovascularization in chronic central serous chorioretinopathy. Eye (Lond). 2016;30(6):805-811.

21. Xu Y, Tan CS. Safety and complications of intravitreal injections performed in an Asian population in Singapore. Int Ophthalmol. 2016; $37(2): 325-332$.

22. Uetani R, Ito Y, Oiwa K, Ishikawa K, Teriyaki H. Half dose vs one-thirddose photodynamic therapy for chronic central serous chorioretinopathy. Eye (Lond). 2012;26(5):640-649. 


\section{Publish your work in this journal}

Clinical Ophthalmology is an international, peer-reviewed journal covering all subspecialties within ophthalmology. Key topics include: Optometry; Visual science; Pharmacology and drug therapy in eye diseases; Basic Sciences; Primary and Secondary eye care; Patient Safety and Quality of Care Improvements. This journal is indexed on

Submit your manuscript here: http://www.dovepress.com/clinical-ophthalmology-journal
PubMed Central and CAS, and is the official journal of The Society of Clinical Ophthalmology (SCO). The manuscript management system is completely online and includes a very quick and fair peer-review system, which is all easy to use. Visit http://www.dovepress.com/ testimonials.php to read real quotes from published authors. 